\title{
The Caenorhabditis elegans gene mek-2 is required for vulval induction and encodes a protein similar to the protein kinase MEK
}

\author{
Kerry Kornfeld, ${ }^{1}$ Kun-Liang Guan, ${ }^{2}$ and H. Robert Horvitz ${ }^{1,3}$ \\ ${ }^{1}$ Howard Hughes Medical Institute, Department of Biology, Massachusetts Institute of Technology, Cambridge, \\ Massachusetts $02139 \mathrm{USA}^{2}$ Department of Biological Chemistry and Institute of Gerontology, The University of Michigan, \\ Ann Arbor, Michigan 48109 USA
}

\begin{abstract}
An evolutionarily conserved signal transduction pathway that utilizes a receptor tyrosine kinase and a Ras protein mediates the induction of vulval cell fates in the nematode Caenorhabditis elegans. We sought new genes that function in this pathway by screening for suppressors of the Multivulva phenotype caused by a mutation that activates the let-60 ras gene. Seven such suppressor mutations defined a new gene involved in vulval induction. We named this gene mek-2, because its predicted protein product is most similar to MEK, a protein-serine/threonine and tyrosine kinase. mek-2 mutations can be arranged in an allelic series. A probable null mutation eliminated vulval induction, and the strongest mutations alter codons conserved in most or all protein kinases. Our genetic analysis showed that mek-2 functions downstream of let-60 ras and is required for ras-mediated signal transduction in vivo. The MEK-2 protein may interact with the products of the lin-45 raf and mpk-1 MAP kinase genes, which also mediate vulval induction.
\end{abstract}

[Key Words: C. elegans; vulval development; mek-2; MEK; protein kinase]

Received January 8, 1995; revised version accepted February 22, 1995.

In the nematode Caenorhabditis elegans, cell signaling induces multipotent precursor cells to form the hermaphrodite vulva, which is used for egg-laying and mating (for review, see Horvitz and Sternberg 1991). A signal from the gonadal anchor cell causes three ventral hypodermal cells, P5.p, P6.p, and P7.p, to adopt vulval fates (Sulston and White 1980; Kimble 1981). P6.p undergoes a reproducible lineage that generates eight descendants, a pattern designated the $1^{\circ}$ vulval cell fate; P5.p and P7.p undergo reproducible lineages that generate seven descendants each, the $2^{\circ}$ vulval cell fate (Sulston and Horvitz 1977). These 22 descendants differentiate as specialized hypodermal cells and form the vulva. If P5.p, P6.p, and P7.p do not receive the anchor cell signal, then they adopt the nonvulval $3^{\circ}$ fate. P3.p, P4.p, and P8.p normally adopt the $3^{\circ}$ fate, but these cells have the potential to respond to the anchor cell signal and adopt vulval fates (Sulston and White 1980; Sternberg and Horvitz 1986). All six of these cells appear to be equivalent in developmental potential, and they are referred to as the vulval equivalence group.

Many mutations have been identified that disrupt vulval induction. Several of the genes defined by these mu-

\footnotetext{
${ }^{3}$ Corresponding author.
}

tations encode proteins similar to proteins involved in signal transduction in other organisms (for review, see Eisenmann and Kim 1994). The lin-3 gene encodes a protein similar to epidermal growth factor (EGF) and likely to be the signal emitted by the anchor cell (Hill and Sternberg 1992). The let-23 gene encodes a protein similar to receptor tyrosine kinases such as the EGF receptor and likely to be the receptor for the anchor cell signal (Aroian et al. 1990). The sem-5 gene encodes a protein with one SH2 (Src-homology-2) domain and two SH3 domains; SEM-5 protein probably binds to activated LET23 protein (Clark et al. 1992a for review, see Schlessinger 1994). The let-60 gene encodes a protein similar to Ras (Han and Sternberg 1990); Ras protein cycles between an inactive, GDP-bound form and an active, GTPbound form and functions downstream of receptor tyrosine kinases in vertebrate cells (for review, see Satoh et al. 1992). A loss-of-function mutation in lin-3, let-23, sem-5, or let-60 can cause all six cells in the vulval equivalence group to adopt the nonvulval $3^{\circ}$ fate, indicating that these genes are required for inductive signaling. Thus, vulval induction is mediated by a highly conserved signal transduction pathway.

It is not yet known how cells adopt the appropriate fates in response to activated ras. In C. elegans, two genes that function downstream of let-60 ras during vul- 
val induction encode protein-serine/threonine kinases: The gene lin-45 encodes a protein similar to Raf (Han et al. 1993), and the gene mpk-1/sur-1 encodes a protein similar to mitogen-activated protein (MAP) kinase (Lackner et al. 1994; Wu and Han 1994). In vertebrate cells, Raf and MAP kinase also function downstream of Ras and act in a pathway that involves a third protein kinase called MEK (MAP kinase or Erk kinase) or MAPKK (MAP kinase kinase; for review, see Marshall 1994). Raf can phosphorylate MEK on two serines and thereby increase the kinase activity of MEK (Alessi et al. 1994; Zheng and Guan 1994). MEK in turn can phosphorylate MAP kinase on a threonine and a tyrosine and thereby increase the kinase activity of MAP kinase (for review, see Ahn et al. 1992). MAP kinase can phosphorylate a variety of proteins, including transcription factors, but the functional significance of these phosphorylations is unclear (for review, see Davis 1993). It is also unclear whether Ras, Raf, MEK and/or MAP kinase regulate more than one downstream target and thus function as branchpoints in the signaling pathway.

To identify genes important for ras-mediated signaling in C. elegans, we screened for mutations that can suppress the formation of ectopic vulval tissue caused by a mutation that activates the let-60 ras gene. We reported previously that a mutation in the gene mpk-1 MAP kinase was identified in this screen (Lackner et al. 1994). Here, we show that seven other mutations identified in this screen define a new gene required for vulval induction. We cloned this gene and found that it encodes a predicted protein that is $55 \%$ identical to human MEK1 protein. Our data demonstrate that a C. elegans homolog of MEK functions downstream of let-60 ras and is essential for vulval induction.

\section{Results}

\section{Isolation of mek-2 mutations}

Gain-of-function mutations in the let-60 ras gene cause P3.p, P4.p, and P8.p to adopt vulval fates; the ectopic vulval tissue that results forms a series of ventral protrusions called the Multivulva (Muv) phenotype (Fig. 1; Ferguson et al. 1987; Beitel et al. 1990). The mutant gainof-function LET-60 protein, which appears to be constitutively active, has glutamic acid at position 13 instead of glycine. To identify genes likely to function downstream of let-60 ras, we screened for mutations that can suppress the let-60 Muv phenotype (Lackner et al. 1994; see also Materials and methods). Thirty-three mutations were identified that reduced the penetrance of the let- 60 Muv phenotype from $93 \%$ to $<10 \%$. The screen was designed so that suppressor mutations that caused a recessive sterile phenotype could be recovered from heterozygous siblings. We also analyzed 10 additional suppressor mutations that were identified previously using a related genetic screen (Beitel et al. 1990).

Each suppressor mutation was mapped to a chromosome. Seven of the mutations that mapped to chromosome I caused variably expressed recessive sterility.
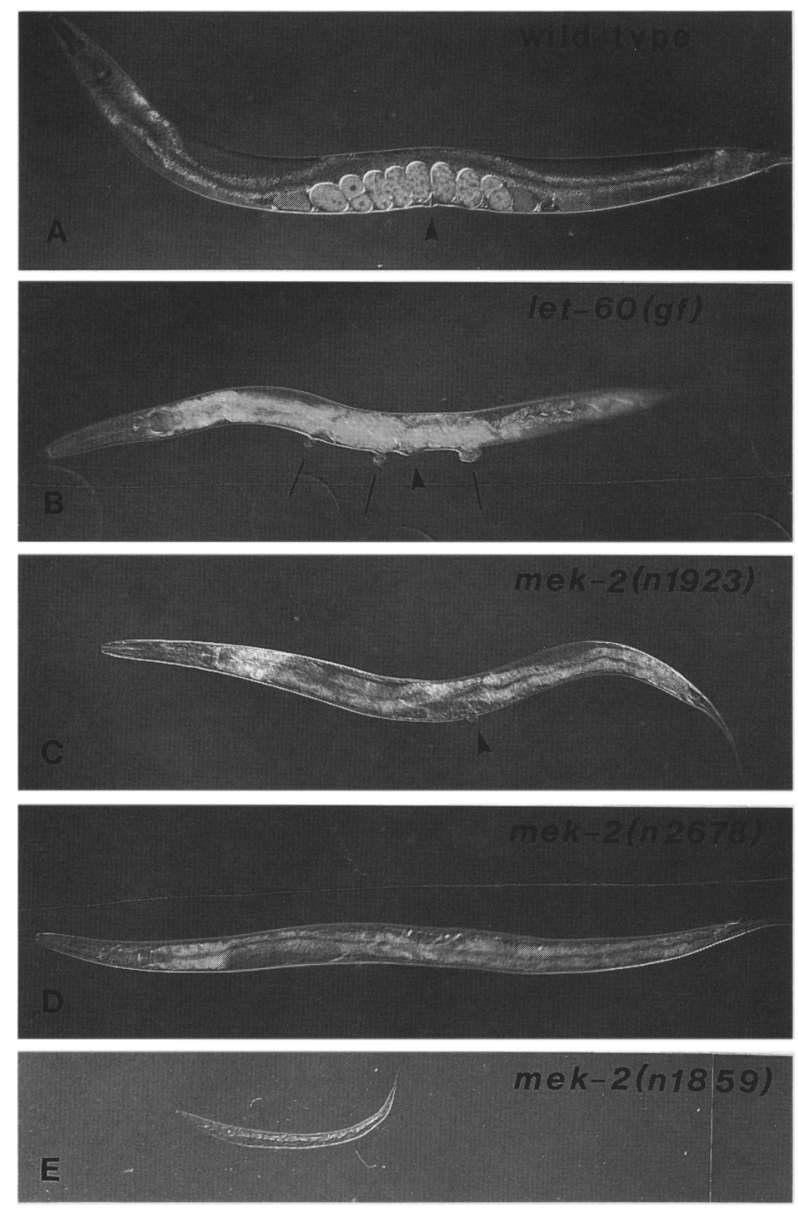

Figure 1. Mek-2 phenotypes. (A) A wild-type adult. The arrowhead indicates a normal vulva. (B) A let-60(gf) mutant. Lines indicate ectopic vulval tissue that defines the Muv phenotype; the arrowhead indicates a normal vulva. (C) A mek-2(n1923) mutant self-progeny of a mek-2(n1923)/ + hermaphrodite. This animal is sterile, and the arrowhead indicates an abnormal, protruding vulva. (D) A mek-2(n2678) mutant self-progeny of a mek-2(n2678)/ + hermaphrodite. This animal is sterile and displays the Vul phenotype. (E) A mek-2(n1859) mutant self-progeny of a mek-2(n1859) hermaphrodite. This animal exhibits the rigid, rod-like larval-lethal phenotype.

Three-factor mapping experiments localized six of these mutations more precisely (see Materials and methods); all of the mapping data are consistent with the conclusion that these mutations lie between the genes sup-11 and ace-2 (Fig. 2A). The sterility was not complemented by the deficiency $t D f 3$ but was complemented by the deficiencies $t D f 4$ and $q D f 3$ (Fig. 2A). These data suggested that these seven mutations might represent a single complementation group.

This prediction was confirmed by showing that each mutation failed to complement at least one of the other mutations for sterility or suppression of the let-60 Muv phenotype (see Materials and methods). We named the gene defined by these mutations mek-2 (mek, MAP kinase or Erk kinase), because subsequent analysis showed 
Figure 2. Genetic and physical map in the mek-2 region. (A) The upper horizontal line represents the genetic map (Wood et al. 1988). Distances between the indicated genes are in map units (m.u.) except where broken by diagonal lines. We positioned mek-2 relative to sup-11 and ace-2 on the basis of three-factor mapping data (see $\mathrm{Ma}$ terials and methods). Lower horizontal lines indicate the extents of deficiencies based on previous analyses (see Materials and methods for references) and data presented in Materials and methods. $(B)$ The upper horizontal line represents a portion of the genetic map described above. Short vertical lines indicate molecularly defined RFLP alleles. (See Materials and methods for data used to map $n P 70, n P 71, n P 72$, and $n P 69 \mid$. Lower horizontal lines represent a portion of the physical map. Labeled DNA fragments are positioned relative to the genetic map except for YAC insert ends broken by diagonal lines (see text for details). Bacteriophage MT\#LLA3 recognizes $n P 59$ (L. Lobel and H.R. Horvitz, unpubl.).

that this gene is predicted to encode a protein similar to the protein kinase MEK (described below). Another $C$. elegans MEK-like gene has been called mek-1 (P. Kayne, pers. comm.). Many mutations have been identified that affect essential genes positioned on the left third of chromosome I (Howell et al. 1988; K. McKim, pers. comm.). One of these mutations, let-537(h294), failed to complement the sterility caused by mek-2(n2516) and thus appears to be an allele of mek-2.

\section{mek-2 mutations caused vulval defects, sterility, and larval lethality}

By examining the penetrances and expressivities of defects caused by mek-2 mutations in let $-60(+)$ animals, we have ordered these mutations in an allelic series. $n 1989, n 1859$, and $n 2537$ appeared to be the weakest mutations. These mutations suppressed the let-60(gf) Muv phenotype (data not shown) but did not usually disrupt vulval formation in let-60(+) animals (Table 1). Two mutations were intermediate in strength, $n 2679$ and $n 1923 . n 2679$ and $n 1923$ mutant hermaphrodites derived from mek-2/ + hermaphrodites frequently displayed abnormal vulval formation characterized either by a protruding vulva or by the lack of a vulva: The latter is known as the Vulvaless (Vul) phenotype (Table 1 and Fig. 1). The three strongest mutations were $n 2516, h 294$, and $n 2678$. Homozygous mutants derived from such mek-2/ + hermaphrodites were almost always Vul (Table 1 and Fig. 1). The Vul phenotype caused by $n 2516$ and n2678 was analyzed in greater detail by examining the fates of cells in the vulval equivalence group. In $n 2516$ and $n 2678$ mutants derived from mek-2/ + hermaphrodites, P5.p, P6.p, and P7.p each generated two descendants, indicating that these cells adopted the nonvulval $3^{\circ}$ fate (Table 2). These data suggest that mek-2 is required for signal transduction during vulval development.

mek-2 mutations caused a sterile phenotype of vari- able expressivity. The mutations $n 1989$ and $n 1859$ could be propagated in homozygous strains. However, n1859 failed to complement the sterility caused by stronger mek-2 mutations demonstrating that this mutation affects fertility (described below). The mutation n2537 caused a partially penetrant recessive sterility (Table 1) and could not be propagated in a homozygous strain. Homozygous $n 2537$ mutants derived from $n 2537 /+$ hermaphrodites deposited 4.5 eggs and generated $0.5 \mathrm{Ll}$ larvae on average ( $n=49$ hermaphrodites). The five strongest mek-2 mutations caused a completely penetrant recessive sterility (Table 1 and Fig. 1). This sterility might result from a defect in oogenesis, as oocytes in strong mutants appear to be blocked in exit from the pachytene stage of meiosis, as are oocytes in certain let-60 and mpk-1 mutants (D. Church, K.-L. Guan, and E. Lambie, in prep.).

Homozygous mek-2 mutants derived from homozygous mek-2 mutant hermaphrodites displayed incompletely penetrant larval lethality. Affected mutant animals appeared to die during the first or second larval stage, and the dead larvae frequently appeared thin and straight (Fig. 1E); this phenotype is indistinguishable from the rigid, rod-like larval lethality caused by mutations in known vulval signaling genes, that is, lin-3, let23, sem-5, let-60, and lin-45 (Ferguson and Horvitz 1985; Beitel et al. 1990; Han et al. 1990, 1993; Clark et al. 1992a). The cellular basis for this lethality has not been determined.

This larval lethality could be rescued by either zygotic or maternal expression of mek-2(+). Whereas self progeny of mek-2(n1859) homozygous mutants displayed $76 \%$ larval lethality (Table 1), the penetrance of the lethality was reduced to $3 \%$ in $n 1859 /+$ animals derived by mating wild-type males and $n 1859 / n 1859$ hermaphrodites $(n=151)$. Furthermore, self progeny of $n 1859)+$ hermaphrodites, one-fourth of which should be animals of genotype $n 1859 / n 1859$, displayed $0 \%$ larval lethality $(n=201)$. Similarly, the other seven mek-2 mutations did 
Table 1. Phenotypes of mek-2 mutants

\begin{tabular}{|c|c|c|c|c|c|c|c|c|c|}
\hline \multirow[b]{2}{*}{ mek-2 allele } & \multicolumn{4}{|c|}{$\mathrm{F}_{1} \mathrm{~m} / \mathrm{m}(\% \text { of adults })^{\mathrm{a}}$} & \multicolumn{5}{|c|}{$\mathrm{F}_{2} \mathrm{~m} / \mathrm{m}(\% \text { of all progeny })^{\mathrm{b}}$} \\
\hline & $\begin{array}{l}\text { abnormal } \\
\text { vulva }^{c}\end{array}$ & $\mathrm{Vul}^{\mathrm{c}}$ & sterile $^{\mathrm{d}}$ & $n^{\mathrm{f}}$ & $\begin{array}{l}\text { abnormal } \\
\text { vulva }^{c}\end{array}$ & $\mathrm{Vul}^{\mathrm{c}}$ & sterile $^{\mathrm{d}}$ & lethal $^{\mathrm{e}}$ & $n^{\mathrm{g}}$ \\
\hline wild type & 1 & 0 & 1 & 150 & 1 & 0 & 1 & 3 & 150 \\
\hline n1989 & 3 & 0 & 3 & 32 & 10 & 0 & 1 & 25 & 245 \\
\hline n1859 & 0 & 0 & 2 & 43 & 4 & 0 & 1 & 76 & 220 \\
\hline n2537 & 16 & 0 & 22 & 49 & 35 & 0 & 52 & 28 & 25 \\
\hline n2679 & 78 & 20 & 100 & 50 & N.A. & N.A. & N.A. & N.A. & \\
\hline n1923 & 38 & 62 & 100 & 45 & N.A. & N.A. & N.A. & N.A. & \\
\hline n2516 & 2 & 98 & 100 & 41 & N.A. & N.A. & N.A. & N.A. & \\
\hline h294 & 0 & 100 & 100 & 36 & N.A. & N.A. & N.A. & N.A. & \\
\hline n2678 & 0 & 100 & 100 & 41 & N.A. & N.A. & N.A. & N.A. & \\
\hline
\end{tabular}

${ }^{a}$ To analyze mek-2/mek-2 $(\mathrm{m} / \mathrm{m})$ self-progeny of mek-2/ + hermaphrodites (the $\mathrm{F}_{1}$ generation), we placed 100-225 eggs from mek-2/ sup-11 dpy-5 hermaphrodites on separate petri plates and allowed them to develop. Animals that did not segregate Sup Dpy progeny or were sterile were judged to have the genotype mek-2/mek-2. For each allele, $\sim 25 \%$ of the adults met these criteria, suggesting that the penetrance of the larval-lethal phenotype is negligible in such animals.

${ }^{b}$ To analyze mek-2/mek-2 self-progeny of mek-2/mek-2 hermaphrodites (the $\mathrm{F}_{2}$ generation), we placed eggs (lines 1-3) or L1 larvae (line 4) on separate petri plates and allowed them to develop. (N.A.) Not applicable.

'Vulva formation was assessed using a dissecting microscope and classified as follows. (Abnormal) Tissue protruded from the vulval opening or animals did not lay eggs normally. Some animals displayed one or two small protrusions near the vulva, as in the hyperinduced (Hin) phenotype described by Aroian and Sternberg (1991). mek-2(n2679) mutants (14\%) and mek-2(n1923) mutants $(11 \%$ ) displayed the Hin phenotype. (Vul) No vulval opening or structures were visible.

d(Sterile) No eggs were observed on the plate, and no hatched progeny were observed on the plate or inside the adult hermaphrodite. e(Lethal) Animals died after hatching but before forming an adult. Most dead larvae had a rigid, rod-like morphology.

$\mathrm{f}(n)$ Number of adult homozygous mutant hermaphrodites analyzed.

$g(n)$ Number of eggs or L1 larvae studied.

not cause measurable larval lethality among homozygous mutants derived from mek-2/ + hermaphrodites (Table 1 footnote). These results indicate that zygotic and maternal expression of mek-2 are at least partially redundant.

The penetrances of the larval lethality of n1989, $n 2537$, and $n 1859$ mutants derived from homozygous mutant hermaphrodites were $25 \%, 28 \%$, and $76 \%$, respectively (Table 1). To investigate how mek-2 mutations that could not be propagated in homozygous strains affect larval viability, we examined progeny from n2516/n1859 and n2678/n1859 hermaphrodites. Many of these trans-heterozygous hermaphrodites were sterile, but some generated a few progeny that hatched. All of

Table 2. Fates of vulval equivalence group cells in $\mathrm{n} 2516$ and $\mathrm{n} 2678$ mutants

\begin{tabular}{llcccccc}
\hline & & \multicolumn{6}{c}{ Cell fate $^{\mathrm{c}}$} \\
\cline { 3 - 7 } Genotype $^{\mathrm{a}}$ & $n^{\mathrm{b}}$ & P3.p & P4.p & P5.p & P6.p & P7.p & P8.p \\
\hline Wild type & many & $3^{\text {oe }}$ & $3^{\circ}$ & $2^{\circ}$ & $1^{\circ}$ & $2^{\circ}$ & $3^{\circ}$ \\
mek-2(n2516) & 10 & $3^{\text {oe }}$ & $3^{\circ}$ & $3^{\circ}$ & $3^{\circ}$ & $3^{\circ}$ & $3^{\circ}$ \\
mek-2(n2678) & 10 & $3^{\text {ee }}$ & $3^{\circ}$ & $3^{\circ}$ & $3^{\circ}$ & $3^{\circ}$ & $3^{\text {oe }}$
\end{tabular}

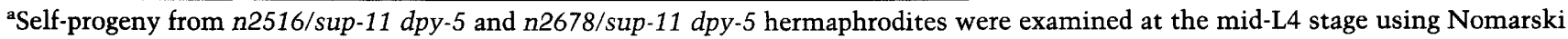
optics and then recovered and allowed to mature. These larvae displayed either a wild-type vulva or no vulva. Ten n2516/sup-11 dpy-5 self-progeny with no vulva at the L4 stage formed sterile Vul adults, demonstrating that their genotype was n2516. Eight $n 2516 /$ sup-11 $d p y-5$ self-progeny with a wild-type vulva at the $\mathbf{L} 4$ stage formed fertile adults that segregated sterile and Sup Dpy progeny, demonstrating that their genotype was n2516/sup-11 dpy-5. Similarly, 10 self-progeny from n2678/sup-11 dpy-5 hermaphrodites displayed no vulva at the L4 stage and had the genotype n2678, whereas 14 self-progeny with normal vulvae at the L4 stage had the genotype n2678/sup-11 dpy-5.

$\mathrm{b}(n)$ Number of animals examined.

${ }^{\circ}$ The $1^{\circ}$ and $2^{\circ}$ cell fates are described in the text. Unless noted otherwise, the $3^{\circ}$ fate indicates that two descendants were observed that adhered to the cuticle. Descendants of P3.p-P8.p were identified on the basis of their positions and appearances as described by Sulston and Horvitz (1977).

${ }^{\mathrm{d} C e l l}$ fates in wild-type animals are from Sulston and Horvitz (1977).

eIn two n2516 animals and four n2678 animals, P3.p did not seem to divide. In many wild-type animals, P3.p does not divide (Sulston and Horvitz 1977). In two n2678 animals, P8.p did not seem to divide. 
the hatched animals from $n 2516 / n 1859(n=12)$ and $n 2678 / n 1859(n=20)$ hermaphrodites died as larvae, and many displayed the rigid rod-like morphology. These results suggest that the alleles n2516 and $n 2678$ provide less of the larval viability function than does n1859.

\section{$\mathrm{n} 2678$ is likely to be a null allele}

The three strongest mek-2 mutations, h294, n2516, and n2678, were candidates for completely eliminating mek-2 activity. To investigate this possibility, we compared the phenotypes caused by n2516 and n2678 with the phenotypes caused by $t D f 3$, a deficiency allele that fails to complement mek-2 mutations (see Fig. 2A). The h294 allele was not analyzed in this way because it contains the same base change as the $n 2516$ allele (described below). First, $n 2516, n 2678$, and $t D f 3$ were examined in trans to the strong allele n2516. n2516/n2516, n2678/ $n 2516$, and $t D f 3 / n 2516$ hermaphrodites were always sterile and Vul, except for one $n 2516$ homozygote (Table 3 ). Second, $n 2516, n 2678$, and $t D f 3$ were examined in trans to the weak allele $n 1859$. n2678 and $t D f 3$ caused a similar spectrum of defects, whereas the defects caused by $n 2516$ were slightly less severe (Table 3 ). Thus, in trans to both strong and weak alleles, $n 2678$ behaved like a mek-2 deficiency, suggesting that $n 2678$ is a null allele. However, it is possible that the $n 2678$ allele retains some mek-2 function that was not measured in

Table 3. $\mathrm{n} 2678$ behaves like the deficiency tDf3

\begin{tabular}{lccccc}
\hline & \multicolumn{5}{c}{$\mathrm{F}_{1} \mathrm{~m} / \mathrm{m}(\% \text { of adults })^{\mathrm{b}}$} \\
\cline { 2 - 6 } Genotype $^{\mathrm{a}}$ & $\begin{array}{c}\text { abnormal } \\
\text { vulva }\end{array}$ & Vul & semisterile & sterile & $n^{\mathrm{c}}$ \\
\hline$n 2516 / n 2516$ & 2 & 98 & 0 & 100 & 41 \\
$n 2678 / n 2516$ & 0 & $100^{\mathrm{d}}$ & 0 & 100 & 28 \\
$t D f 3 / n 2516$ & 0 & 100 & 0 & 100 & 54 \\
$n 2516 / n 1859$ & 29 & 0 & 6 & 41 & 17 \\
$n 2678 / n 1859$ & 55 & 3 & 16 & 55 & 31 \\
$t D f 3 / n 1859$ & 47 & 0 & 12 & 68 & 34 \\
\hline
\end{tabular}

${ }^{a} n 2516 / n 2516$ animals were self-progeny of $n 2516 /$ sup- 11 dpy-5 hermaphrodites. $n 2678 / n 2516$ and $t D f 3 / n 2516$ animals were generated by mating n2516/sup-11 dpy-5 males and n2678/sup11 dpy-5 or $t D f 3$ dpy-5/fog-1 unc- 11 hermaphrodites, respectively. Animals containing $n 1859$ were generated by mating n1859/sup-11 dpy-5 males and either n2516/sup-11 dpy-5, n2678/sup-11 dpy-5, or tDf3 dpy-5/fog-1 unc-11 hermaphrodites. For each mating, between 230 and 400 cross-progeny were placed on individual petri plates, and their phenotypes and progeny were examined. mek-2 mutants were identified by their vulval and fertility phenotypes and their failure to segregate chromosome I markers. In each case, animals that appeared to be mek-2 mutants represented $\sim 25 \%$ of the adult hermaphrodite progeny.

bHeadings are described in the footnote to Table 1, except that semisterile animals produced one or more eggs, but no L1 larvae were observed.

c $(n)$ Number of adult mutant hermaphrodites analyzed.

${ }^{\mathrm{d}}$ Eighteen percent of these animals displayed the Hin phenotype (see Table 1 footnote) in addition to appearing Vul. these assays. The $n 2516$ allele appears to retain a small amount of mek-2 activity.

The eight mek-2 alleles can be arranged in an allelic series with increasing phenotypic consequences in the order $n 1989, n 1859$ and $n 2537, n 1923$ and $n 2679, n 2516$ and h294, n2678. The series culminates with a probable null mutation, $n 2678$. Thus, these mutations may progressively reduce the activity of the mek-2 gene.

\section{Physical mapping and cloning of mek-2}

To learn more about how mek-2 affects vulval induction, we began molecular studies of this gene. A physical map of the C. elegans genome has been assembled consisting of overlapping fragments of genomic DNA cloned in cosmid or yeast artificial chromosome (YAC) vectors (Coulson et al. 1988). To position mek-2 on the physical map, we used DNA from the region to identify restriction fragment length polymorphisms (RFLPs) and then mapped these RFLPs relative to mek-2 (Ruvkun et al. 1989; see also Materials and methods).

Figure 2B illustrates the positions of four newly identified RFLP alleles. $n P 69$, which was identified using the cosmid C45E1, mapped right of mek-2. nP70 and nP71, which were identified using the bacteriophage $\lambda 5-4$ and the left end of YAC Y54E10, respectively, mapped left of mek-2. nP72, which was identified using the right end of YAC Y71F9, was not separated from mek-2 by 20 recombination events between sup-11 and mek-2 or 20 recombination events between ace-2 and mek-2. Therefore, the right end of Y71F9 appeared to be extremely close to mek-2.

The physical map near the right end of Y71F9 contains no cosmids, and we failed to isolate DNA from this region using a genomic DNA library cloned in bacteriophage $\lambda$, suggesting DNA from this region propagates poorly in Escherichia coli. However, using a probe from the right end of Y71F9 we were able to isolate $4.7 \mathrm{~kb}$ of contiguous genomic DNA in the plasmids pKK9 and pKK10 (Fig. 2B; see also Materials and methods). In parallel with this positional cloning approach, we sought $C$. elegans homologs of the protein kinase MEK, because MEK is involved in ras-mediated signaling in vertebrates (for review, see Marshall 1994). Using degenerate oligonucleotide primers based on conserved regions of MEK proteins and polymerase chain reaction (PCR) amplification, a small fragment of DNA was generated and used to isolate a full-length $C$. elegans cDNA. This cDNA is predicted to encode a protein that contains 387 amino acids and is $55 \%$ identical to human MEKl and $56 \%$ identical to Drosophila D-Mek. The isolation and sequence of this cDNA are described in detail elsewhere (Wu et al., this issue).

This cDNA hybridized to the genomic DNA insert of pKK9 and identified the RFLP nP72 (data not shown). Thus, genomic DNA cloned using a positional approach and a cDNA identified using a candidate gene approach overlapped and both identified a RFLP that was inseparable from the mek-2 gene. 
mek-2 gene structure and the sequences of mutant alleles

To test the hypothesis that the MEK-related cDNA and the mek-2 mutations define the same gene, we determined the sequences of the coding region defined by the cDNA using DNA from each of the eight mek-2 mutants. We used oligonucleotide primers and PCR amplification to generate DNA fragments that contained the coding region and exon/intron junctions; the sequences of these fragments were then determined. Before using this approach, we had to determine the positions of the introns and the sequences of the introns adjacent to the exons. Because it had been difficult to clone genomic DNA from the region, we used the newly developed technique of long PCR amplification to obtain quantities of genomic DNA adequate for sequence determination without further cloning (Barnes 1994; Cheng et al. 1994). Specifically, oligonucleotide primers positioned at the $5^{\prime}$ and $3^{\prime}$ ends of the $1.3-\mathrm{kb}$ cDNA were used to amplify an $\sim 7 \mathrm{~kb}$ fragment from genomic DNA. We obtained partial sequences of this PCR-amplified DNA using oligonucleotide primers spaced at regular intervals in the cDNA (see Materials and methods). This analysis showed that the coding region defined by the cDNA is interrupted by six introns and established the exon-proximal sequence of each intron (Fig. 3A). This approach, which rapidly yielded the position and exon-proximal sequence of each intron without the need to clone genomic DNA, is likely to be generally applicable.

Using this information, we determined the DNA sequence of the coding region from amino acid 8 to 387 and the exon-proximal portion of each intron for each of the eight mek-2 alleles (see Materials and methods). Each of the eight mek-2 alleles had a single-base change compared with the sequence of the wild-type allele, and each of these changes alters a conserved codon (Fig. 3). Together, the finding that the mek-2 mutations and the cDNA are positioned in the same small interval of the physical map and the finding that all eight mek-2 alleles have missense mutations in the MEK-like open reading frame confirm the hypothesis that this cDNA and the mek-2 mutations define the same gene.

\section{mek-2 appears to function downstream of let-60 ras} and upstream of lin-1

Mutations in several genes involved in vulval formation can cause a Muv phenotype. To investigate the relationships between these genes and mek-2, we performed genetic epistasis experiments by examining the phenotypes of double mutants containing a Muv mutation and mek-2(n2516), a strong loss-of-function mutation that causes a Vul phenotype (Table 4). If a double mutant displays a Vul phenotype, then mek-2 function is still required for vulval development, suggesting that mek-2 functions downstream of the Muv gene. Conversely, if a double mutant displays a Muv phenotype, then mek-2 is not required for vulval development and is likely to function upstream of the Muv gene. These interpretations assume that the two genes act in a linear pathway; either epistatic interaction is also consistent with the hypothesis that the two genes act in parallel pathways.

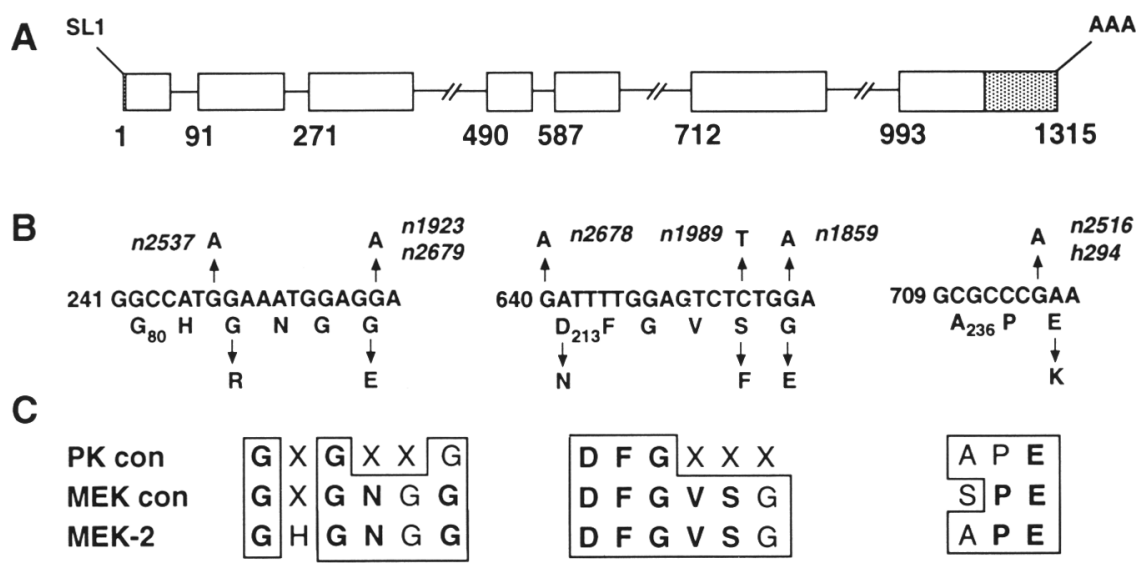

A Figure 3. mek-2 gene structure and mutations. (A) Boxes represent exons; untranslated regions are stippled. The predicted initiator ATG starts at nucleotide 4. The number of the first nucleotide in each exon is shown below; the last nucleotide in exon 7 is shown. Horizontal lines represent introns. The sizes of introns $1-6$ are 60,55 , $\sim 3900,50, \sim 840$, and $\sim 1400 \mathrm{bp}$, respectively (see Materials and methods). Diagonal lines labeled SL1 and AAA indicate the probable sites of SLl trans-spliced leader attachment and poly(A) addition, respectively (Wu et al., this issue). (B) Three stretches of nucleotide sequence that begin at positions 241, 640, and 709 and encode amino acids 80-85, 213-218, and 236-238, respectively, are shown. Arrows above the nucleotide sequence indicate base changes in the labeled alleles. Each change was a $\mathrm{GC} \rightarrow \mathrm{AT}$ transition, which is the characteristic mutation caused by EMS, the mutagen used to generate all of these mutations (Coulondre and Miller 1977). Arrows below the inferred translation indicate amino acids encoded by these alleles. $(C)$ The protein kinase consensus (PK con) is based on an alignment of 38 protein-serine/threonine kinases and 27 protein-tyrosine kinases (Hanks et al. 1988). Boldface type indicates a residue present in 64 or 65 kinases. Regular type indicates a residue present in 52-63 kinases. (X) No single residue was present in $>51$ kinases. The MEK consensus (MEK con) is based on an alignment of MEK1 (Crews et al. 1992), MEK2 (Zheng and Guan 1993), D-Mek (Tsuda et al. 1993), STE7 (Teague et al. 1986), BYR1 (Nadin-Davis and Nasim 1988), PBS2 (Boguslawski and Pulazzi 1987), and wisl (Warbrick and Fantes 1991). Boldface type indicates residues present in seven MEK proteins. Regular type indicates residues present in four to six MEK proteins. (X) No single residue was present in more than three MEK proteins. MEK-2 residues shown in boldface type are conserved among the seven MEK proteins. Boxes indicate residues conserved among $C$. elegans MEK-2, most or all MEK proteins, and/or most or all protein kinases. 
Table 4. Interactions between mek-2 and vulval determination genes

\begin{tabular}{|c|c|c|}
\hline Genotype $^{a}$ & Percent Muv $v^{b}$ & $n^{\mathrm{c}}$ \\
\hline mek-2(n2516)/+; lin-3(sy1s1) & 100 & 296 \\
\hline mek-2(n2516); lin-3(syIs1) & 0 & 207 \\
\hline mek-2(n2516) $/+; \operatorname{lin}-15(n 309)$ & 100 & 123 \\
\hline mek-2(n2516); lin-15(n309) & 0 & 213 \\
\hline mek-2(n2516)/ + let-60(gf) & 91 & 231 \\
\hline mek-2(n2516); let-60(gf) & 0 & 156 \\
\hline mek-2(n2516)/ $+\operatorname{lin}-1(e 1275)^{\mathrm{e}}$ & 100 & 233 \\
\hline mek-2(n2516); lin-1(e1275) & 99 & 154 \\
\hline
\end{tabular}

${ }^{a}$ n2516-containing mutants were derived from n2516/sup-11 dpy-5 hermaphrodites; sterile animals were counted as n2516 homozygotes, and fertile non-Sup non-Dpy animals were counted as $n 2516 /$ + heterozygotes. None of the Muv mutations suppressed the mek-2 sterility.

${ }^{b}$ Muv animals displayed one or more ventral protrusions displaced from the position of the vulval opening.

c(n) Number of animals scored.

din-3(syIs1) is an array containing multiple copies of the wildtype lin-3 gene.

'Experiments with lin-1(e1275), a temperature-sensitive mutation, were done at $25^{\circ} \mathrm{C}$.

lin-3 encodes a protein similar to EGF and likely to be the signal for vulval formation (Hill and Sternberg 1992). lin-15 encodes two novel proteins that negatively regulate vulval induction (Clark et al. 1994; Huang et al. 1994). Both genes appear to function outside the Pn.p cells and upstream of the let-23 receptor tyrosine kinase (Herman and Hedgecock 1990; Clark et al. 1992b; Hill and Sternberg 1992). The Muv phenotypes displayed by transgenic animals that contain multiple copies of the wild-type lin-3 gene or mutants that contain a lin-15 null allele were completely suppressed by mek-2(n2516) (Table 4). The mek-2 mutations were isolated as suppressors of the let-60 ras Muv phenotype, and mek-2(n2516) completely suppressed the let-60(n1046gf) Muv phenotype (Table 4). Thus, mek-2 is likely to function downstream of lin-3, lin-15, and let-60 ras.

lin-1 encodes a protein that is similar to ETS domaincontaining transcription factors (G. Beitel and H.R. Horvitz, in prep.). Loss-of-function mutations in lin-1 cause a Muv phenotype that is epistatic to mutations in genes encoding signaling molecules such as lin-3, let-23, let60, and mpk-1 (Ferguson et al. 1987; Han et al. 1990; Lackner et al. 1994; Wu and Han 1994). Thus, lin-1 appears to prevent vulval formation, and the signaling pathway seems to inactivate lin-1 and thereby permit vulval formation. The Muv phenotype caused by a lossof-function lin-1 mutation was not suppressed by mek2(n2516) (Table 4). Furthermore, the larval lethality caused by mek-2(n1859) was suppressed by a mutation in lin-1: mek-2(n1859); lin-1(e1275) hermaphrodites segregated $0 \%$ rod-like larval lethal progeny $(n=399)$. However, the sterile phenotype caused by mek-2(n2516) was not affected by the lin-1 mutation (see Table 4 footnote). Therefore, lin-1 appears to function downstream of mek-2 in vulval development and in the pathway re- quired for larval viability but not in the pathway required for fertility.

\section{Discussion}

The severities of mek- 2 mutations are consistent with structural and functional studies of known protein kinases

Each of the six distinct mek-2 alleles appears to encode a protein with a single amino acid substitution. Aspects of the structures and functions of these mutant MEK-2 proteins can be inferred from studies of other protein kinases. Three-dimensional crystal structures of four protein kinases are known: cAMP-dependent protein kinase (cAPK), MAP kinase, cyclin-dependent protein kinase 2, and twitchin (Knighton et al. 1991; DeBrondt et al. 1993; $\mathrm{Hu}$ et al. 1994; Zhang et al. 1994). These structures revealed that conserved residues in the catalytic domain are similarly arranged in all four proteins. This finding suggests that protein kinases in general have similar structures and that the known structures can be used to infer the positions and functions of conserved residues in MEK-2. In addition, roles of some conserved residues have been defined by biochemical studies of mutant protein kinases.

Our genetic analysis suggested that the $n 2678$ mutation is a null allele. The $n 2678$ mutant MEK-2 protein has an asparagine at position 213 instead of an aspartic acid that is universally conserved (Fig. 3; Hanks et al. 1988). The three-dimensional structure of cAPK shows that this aspartic acid binds the magnesium that bridges the $\beta$ - and $\gamma$-phosphates of ATP and helps orient the phosphate moiety that is transferred (Taylor et al. 1992). Every charged residue in yeast CAPK has been changed to alanine in a scanning mutagenesis study (Gibbs and Zoller 1991). The change that most diminished yeast cAPK activity was a substitution of this aspartic acid. In addition, changing this aspartic acid to alanine in rabbit MAPKK1 creates a protein with no catalytic activity as measured biochemically (Alessi et al. 1994). These data are consistent with our results, which suggested that MEK-2(D213N) protein has no activity. The structural data suggest that this mutant MEK-2 protein cannot correctly orient the ATP and therefore cannot catalyze transfer of the phosphate moiety.

The strong alleles $n 2516$ and h294 had the same base substitution and encode proteins with a lysine at position 237 instead of a glutamic acid that is almost completely conserved (Fig. 3; Hanks et al. 1988). The threedimensional structure of CAPK shows that the affected glutamic acid plays an important structural role (Taylor et al. 1992). When this residue is changed to alanine in yeast cAPK, the mutant enzyme retains only $0.9 \%$ of wild-type activity (Gibbs and Zoller 1991). It is likely that the catalytic domain of MEK-2(E237K) has an abnormal structure and is severely impaired. Thus, the severities of the mutations $n 2678$ and n2516 in C. elegans mek-2 correlate well with the severities of similar mutations in yeast cAPK. 
Three mek-2 alleles encode proteins with substitutions in the conserved G- $X-\mathrm{G}-X-X-\mathrm{G}$ protein kinase motif (Hanks et al. 1988). The intermediate-strength alleles $n 1923$ and $n 2679$ had the same base change and encode proteins with glutamic acid in place of the highly conserved final glycine (Fig. 3). The weaker allele n2537 encodes a protein with arginine in place of the almost completely conserved second glycine (Fig. 3). The structure of cAPK shows that the G- $X$-G- $X-X-\mathrm{G}$ motif forms a loop that specifically positions the nontransferable $\beta$-phosphate of ATP (Taylor et al. 1992). Changing the final conserved glycine to valine in the insulin receptor creates a mutant protein with $<10 \%$ of wild-type autophosphorylation activity (Odawara et al. 1989). Changing either the second or final glycine in MEK-2 presumably reduces ATP binding and thereby protein kinase activity.

The weak mutations $n 1989$ and $n 1859$ affect adjacent codons: $n 1989$ encodes MEK-2(S217F), and n1859 encodes MEK-2(G218E). Although residues at these positions are not conserved in all protein kinases, these residues are conserved in most or all MEK proteins, and they may have important functions. In addition, these residues are very close to the critical aspartic acid at position 213 , and they are positioned in the center of the catalytic site (Taylor et al. 1992). It is possible that substituting phenylalanine for serine or aspartic acid for glycine at these positions disrupts the catalytic site.

\section{$M E K-2$ protein may interact with $L I N-45$ Raf and MPK-1 MAP kinase}

Vertebrate MEK was identified in cell extracts and purified on the basis of its ability to phosphorylate and activate MAP kinase (for review, see Ahn et al. 1992). Purified MEK can phosphorylate serine, threonine, and tyrosine residues. This broad specificity is expected for a MAP kinase activator, because MAP kinase requires threonine and tyrosine phosphorylation for activity. MEK must be phosphorylated to be active, and the protein kinase Raf can phosphorylate two critical serines and thereby activate MEK (Cowley et al. 1994; Zheng and Guan 1994). Our data showed that mek-2 functions downstream of let-60 ras and upstream of lin-1: lin-45 raf and mpk-1 MAP kinase also function in this interval of the vulval induction pathway (Han et al. 1993; Lackner et al. 1994; Wu and Han 1994). These findings suggest that LIN-45 phosphorylates and activates MEK-2, which then phosphorylates MPK-1. However, our data do not establish the order of action of these three genes or whether these gene products interact directly. Figure 4 shows a model of protein function during C. elegans vulval induction based on genetic analyses in C. elegans and biochemical analyses of similar proteins from other organisms.

Genes similar to MEK have been analyzed genetically in the fruit fly Drosophila melanogaster and in the yeasts Saccharomyces cerevisiae and Schizosacharomyces pombe. In $D$. melanogaster, $D$-mek functions downstream of $D$-raf in the pathways that mediate differenti-

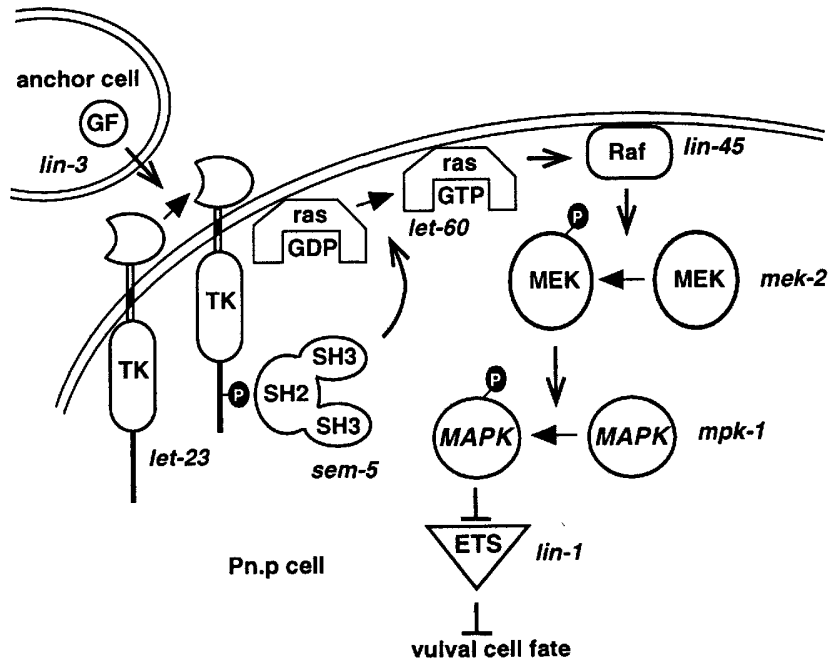

Figure 4. A model for signal transduction during vulval induction. The order of gene action is based on genetic epistasis experiments in C. elegans, except for the relative order of let-23 and sem-5 and the relative order of lin-45, mek-2, and mpk-1. Biochemical activities are inferred from analyses of similar proteins in other organisms (see text for details). (GF) Growth factor; (TK) receptor tyrosine kinase; (MAPK) MAP kinase; (ETS) ETS domain-containing protein; ( $\mathrm{P}$ in the black circle) phosphorylation. This figure is adapted from Clark et al. (1992b).

ation of terminal structures of the embryo and the R7 photoreceptor cell (Tsuda et al. 1993; Hsu and Perrimon 1994). A Drosophila MAP kinase, the product of the rolled gene, also functions in these pathways (Brunner et al. 1994). In S. cerevisiae and S. pombe, the mating response pathways are mediated by a series of conserved protein kinases that include the MEK homologs STE7 and BYR1, respectively (for review, see Errede and Levin 1993); these kinases function upstream of the MAP kinase homologs KSS1/FUS3 and SPK1, respectively. Thus, MEK and MAP kinase function together in signaling pathways in vertebrates, insects, yeasts, and nematodes.

In addition to Raf, Mos and MEK kinase can phosphorylate vertebrate MEK, suggesting that MEK may act as an integration point for several signaling pathways (Lange-Carter et al. 1993; Posada et al. 1993). Furthermore, the upstream activators in both yeasts, STE11 and BYR2, are similar to MEK kinase (Errede and Levin 1993). These findings suggest that mek-2 might be regulated by multiple upstream activators, either in a single cell or in distinct cells. Our data suggest lin-45 raf is the only activator that regulates mek-2 during $C$. elegans vulval development. Loss-of-function mutations in mek-2 and lin-45 raf cause the same Vul phenotype (Han et al. 1993). If other proteins activated mek-2 during vulval development, then lin-45 raf mutations might cause a less severe phenotype than mek-2 mutations. Furthermore, mek-2 and lin-45 raf mutations cause the same morphologically distinctive larval lethality, which suggests that lin-45 uniquely regulates mek-2 at a second 
time during development. It remains possible that mek-2 is regulated by upstream activators other than or in addition to Raf at other times during development. For example, the sterile phenotype caused by lin-45 raf mutations has not been characterized extensively and may differ from that caused by mek-2 mutations. In addition, mek-2 may function at additional times and sites during C. elegans development.

\section{mek-2 function is essential for ras-mediated signal transduction}

Some evidence suggests that signaling pathways involving a receptor tyrosine kinase and a Ras protein might branch upstream of MEK. For example, receptor tyrosine kinases can interact with multiple $\mathrm{SH} 2$-containing proteins (for review, see Schlessinger and Ulrich 1992), and activated Ras can bind multiple potential effectors, such as phosphatidylinositol-3-OH kinase and Raf (RodriguezViciana et al. 1994; for review, see McCormick 1994). Our results show that the anchor cell signal is not transmitted in the absence of mek-2: A null mutation in mek2 , loss-of-function mutations in upstream signaling genes, and ablation of the anchor cell cause the same Vul phenotype (Horvitz and Sternberg 1991). These results suggest that the vulval inductive signaling pathway does not have an essential branch upstream of mek-2. If such a branch does exist, it must not act in the absence of mek-2 activity. A null mutation in the mpk-1 MAP kinase gene, which presumably acts after mek-2, has not yet been identified. Thus, mek-2 appears to be the most downstream gene that is known to be required for full transmission of the anchor cell signal during C. elegans vulval induction.

Our results are consistent with findings from studies of Drosophila, in which loss-of-function mutations in $D$-mek and upstream signaling genes such as $D$-raf cause similar phenotypes (Tsuda et al. 1993). Furthermore, the expression of a constitutively active, mutant MEK protein can transform cultured vertebrate cells, and expression of a dominant-negative mutant MEK protein can interfere with some cellular responses to growth factors, suggesting that in vertebrates as well MEK is necessary and can be sufficient to effect signal transduction (Cowley et al. 1994; Mansour et al. 1994). Taken together, these findings suggest that the crucial role that MEK plays in C. elegans vulval induction has been conserved in a wide variety of ras-mediated signaling pathways from species as diverse as C. elegans, Drosophila, and vertebrates.

\section{Materials and methods}

General methods and strains

C. elegans strains were cultured as described by Brenner (1974) and were grown at $20^{\circ} \mathrm{C}$ unless noted otherwise. The wild-type strain and parent of all mutant strains was N2. The RFLP studies used RC301, a separate isolate from the wild (R. Cassada, pers. comm.). Unless noted otherwise, mutations used in this study are described by Wood et al. (1988) and are listed below.
LGI: sup-11(n403); ace-2(g72); fog-1(q187); bli-3(e767); lin17(n671); unc-11(e47); dpy-5(e61); let-537(h294), which is called mek-2(h294) (Howell et al. 1988; K. McKim, pers. comm.); mek-2(q425) (D. Church, K.-L. Guan, and E. Lambie, in prep.); mek-2(n1859, n1989, n1923) (Beitel et al. 1990); mek2(n2516, n2537, n2678, n2679) (this study); $t D f 3$ (Schnabel and Schnabel 1990); $t D f 4$ (R. Schnabel, pers. comm.); qDf3 (Barton and Kimble 1990); $h D p 18 ; h D p 62 ; h D p 72$ (McKim and Rose 1990). LGIV: lin-1(e1275ts); let-60(n1046gf), which is called let60(gf) in this paper. LGX: ace-1(p1000); lin-15(n309); lin3 (syIs1) is an array containing multiple copies of the wild-type lin-3 gene integrated into the X chromosome (Hill and Sternberg 1992).

\section{Identification of let-60 ras Muv suppressors}

At $22.5^{\circ} \mathrm{C}$, the Muv phenotype was displayed by $93 \%$ of let60 (n1046 gf) mutants $(n=716)$. To isolate mutations that suppress this Muv phenotype, we mutagenized let-60(n1046gf) hermaphrodites with ethyl methanesulfonate (EMS) (Brenner 1974). $F_{1}$ self-progeny (2794) of mutagenized hermaphrodites were picked to separate petri plates, and $F_{2}$ self-progeny were examined. If $F_{1}$ animals segregated $>25 \%$ non-Muv progeny, several non-Muv $F_{2}$ animals were picked to separate petri plates and $F_{3}$ self-progeny were examined. If $F_{2}$ animals consistently segregated $>90 \%$ non-Muv $\mathrm{F}_{3}$ progeny, the newly induced mutation was investigated further. If $F_{2}$ animals were sterile, the newly induced mutation was investigated further if $>90 \%$ of the sterile $\mathrm{F}_{2}$ animals were non-Muv. Suppressor mutations that caused a recessive sterile phenotype were maintained in heterozygous strains. Thirty-three such independently derived mutations were identified. This screen was performed at $22.5^{\circ} \mathrm{C}$. In a related screen described previously, non-Muv $F_{1}$ self-progeny of mutagenized lin-8(n111); let-60(gf) hermaphrodites were picked to separate petri plates at $25^{\circ} \mathrm{C}$ (Beitel et al. 1990). Ten extragenic mutations identified in this screen met the criteria described above and were investigated further.

\section{Mapping mek-2 mutations}

The suppression of the let- 60 Muv phenotype caused by $n 1859$ and $n 1989$ and the sterility and vulval defects caused by $n 2516$ were mapped to chromosome I by examining linkage between these phenotypes and genetic markers in the center of each of the six C. elegans chromosomes (data not shown). We showed the sterility and vulval defects caused by $n 2537$ and $n 1923$ to be linked to the RFLP hP4 on chromosome I and mapped them left of the RFLP stP124 on chromosome I using the method of Williams et al. (1992; data not shown). We used three-factor crosses to map further the lethality caused by $n 1859$ and the sterility and vulval defects caused by $n 2537, n 1923, n 2679$, $n 2516$, and $n 2678$. Of Lin non-Bli progeny from $n 2537 / b l i-3$ lin-17 hermaphrodites, $0 / 12$ segregated n2537. Of Dpy non-Sup progeny from $n 1859 /$ sup -11 dpy-5 hermaphrodites, $26 / 28$ segregated $n 1859$. Of Dpy non-Sup progeny from n1923/sup-11 dpy-5 hermaphrodites, $22 / 24$ segregated $n 1923$. Of Lin non-Bli progeny from $n 1923 /$ bli-3 lin-17 hermaphrodites, 0/11 segregated n1923. Of Dpy non-Sup progeny from n2679/sup-11 dpy-5 hermaphrodites, 16/16 segregated n2679. Of Unc non-Fog progeny from $n 2516 /$ fog- 1 unc-11 hermaphrodites, $15 / 15$ segregated n2516. Of Lin non-Fog progeny from n2516/lin-17 fog-1 hermaphrodites, $11 / 18$ segregated $n 2516$. Of Ace- 2 non-Sup progeny from $n 2678 /$ sup-11 ace-2; ace-1 hermaphrodites, 8/11 segregated $n 2678$. Of Dpy non-Sup progeny from n2678/sup-11 dpy-5 hermaphrodites, $17 / 18$ segregated n2678. These data showed that $n 2678$ lies between sup-11 and ace-2. All of our 
data are consistent with the conclusion that the other mek-2 mutations also lie in this interval.

\section{mek-2 complementation tests}

$n 1859$ and $n 1989$ failed to complement for the suppression of the let-60 Muv phenotype: $<1 \%$ of the progeny from $n 1859 /$ n1989; let-60(gf) hermaphrodites displayed a Muv phenotype $(n=105)$. Complementation tests for the sterile phenotype were done by mating males heterozygous for one of the mutations to be tested and hermaphrodites heterozygous for the second mutation. Progeny from mated hermaphrodites that produced $\sim 50 \%$ male progeny were assumed to be cross progeny. If $\sim 25 \%$ of the hermaphrodite cross progeny were sterile, then we judged that the two mutations failed to complement. n2516 failed to complement the sterility caused by $n 1859, n 1923, n 2537$, $n 2678, n 2679, h 294$, and $q 425 . t D f 3$ failed to complement the sterility and vulval defects caused by $n 2516$ and $n 1859$ but complemented the uncoordinated phenotype caused by ace-2. The sterility and vulval defects caused by n2516 were complemented by $t D f 4$ and $q D f 3$. The sterility and vulval defects caused by $n 2678$ were complemented by the duplication $h D p 72$ but were not complemented by $h D p 62$ or $h D p 18$.

\section{Identification of RFLPS}

Unless noted otherwise, molecular biology techniques were performed according to Sambrook et al. (1989). We identified RFLPs by hybridizing fragments of genomic DNA from the region (derived from cosmid clones, YAC ends, and bacteriophage $\lambda$ clones) to Southern blots containing restriction enzyme-digested DNA from N2 and RC301, two diverged wild-type strains. By testing between 10 and 39 different restriction enzymes, we sometimes identified an enzyme that cleaved RC301 DNA and N2 DNA into fragments of different sizes in the region detected by the hybridization probe. The RC301 locus that yielded a distinctive pattern of fragments after digestion with AvaII and hybridization to cosmid C45El was assigned the allele name $n P 69$. The oligonucleotide primers 5'-CCTCAAACTCCATCAAATCC and 5'-CTGATGATCTTCTCGCGG and PCR amplification were used to generate an $\sim 120$ bp fragment corresponding to the left end of YAC Y54E10/A. Coulson, pers. comm.). The RC301 locus that yielded a distinctive pattern of fragments after digestion with EcoRI and hybridization to this fragment was assigned the allele name $n P 71$. The oligonucleotide primers $5^{\prime}$-CCTGATGCCGAGCTTCATG and 5' -GCAGCAGTGCATGGGCATTG and PCR amplification were used to generate a 63-bp fragment corresponding to the right end of YAC Y71F9 (A. Coulson, pers. comm.; this paper). The RC301 locus that yielded a distinctive pattern of fragments after digestion with $B s a \mathrm{BI}$ and hybridization to this fragment was assigned the allele name $n P 72$. Y71F9 was radiolabeled and used to probe $\sim 66,000$ plaques (14 genome equivalents) from two genomic DNA libraries cloned in bacteriophage $\lambda$ [made by H. Browning (University of Indiana, Bloomington) and J. Sulston (MRC, Cambridge, UK)]. Thirty-one hybridizing bacteriophage were identified and used as hybridization probes. The RC301 locus that yielded a distinctive pattern of fragments after digestion with $X b a I$ and hybridization to $\lambda 5-4$ was assigned the allele name $n P 70$.

\section{Mapping RFLPS}

To map RFLP alleles relative to sup-11 and mek-2, we mated RC301 males (genotype nP70 nP71 nP72 nP69) to sup-11 mek2(n2516)/sup-11 dpy-5 hermaphrodites and selected cross progeny with the genotype sup-11 mek-2/nP70 nP71 nP72 nP69.
Next, we selected 20 Sup non-Mek-2 recombinants; these animals were scrawny and fertile. We identified animals homozygous for the recombinant chromosome on the basis of their failure to segregate sterile progeny. To analyze $n P 69, n P 70$, $n P 71$, and $n P 72$, we extracted DNA from these animals, digested it with the appropriate restriction enzyme, prepared Southern blots, and hybridized the blots to the appropriate radiolabeled DNA fragment. These recombinant animals had the following genotypes: $n P 70 n P 71 n P 72 n P 69(n=14), n P 71 n P 72$ $n P 69(n=4), n P 72 n P 69(n=2)$. These data showed that $n P 70$ and $n P 71$ lie between sup-11 and mek-2: Of 20 recombination events between sup-11 and mek-2, 6 occurred between $n P 70$ and mek-2, whereas two of these recombination events occurred between $n P 71$ and mek-2.

To map RFLP alleles relative to mek-2 and ace-2, we obtained 20 Ace-2 non-Mek-2 recombinants from mek-2(n2678) ace-2/ nP70 nP71 nP72 nP69; ace-1 hermaphrodites. We identified and analyzed animals homozygous for the recombinant chromosome as described above. These animals had the following genotypes: $n P 70 n P 71 n P 72 n P 69(n=11), n P 70$ nP71 nP72 ( $n=9)$. These data showed that $n P 69$ lies between ace-2 and mek-2: Of 20 recombination events between ace- 2 and mek-2, 9 occurred between mek-2 and nP69.

\section{Isolation of mek-2 DNA}

To attempt to isolate DNA from the mek-2 region, we radiolabeled the 63-bp DNA fragment from the right end of Y71F9 and screened $\sim 250,000$ plaques (50 genome equivalents) from a genomic DNA library cloned in $\lambda$ DASH (made by $\mathrm{H}$. Browning). No hybridizing plaques were detected. To generate a restriction enzyme cleavage map of DNA near the right end of Y71F9, we digested $C$. elegans genomic DNA with restriction enzymes, either singly or in combinations, prepared Southern blots, and hybridized the blots to the 63-bp probe. We deduced the following order and spacing of restriction enzyme sites: BamHI $(2.5$ kb) EagI $(1.2 \mathrm{~kb})$ ClaI $(1.0 \mathrm{~kb})$ BamHI. The 1.2-kb EagI-ClaI fragment appeared to contain the right end of Y71F9. To clone DNA fragments from this region, we digested $10 \mu \mathrm{g}$ of C. elegans genomic DNA with BamHI and ClaI or EagI and BamHI, fractionated this DNA on an agarose gel, and isolated the regions of the gel containing $3.7-\mathrm{kb}$ and $2.2-\mathrm{kb}$ fragments, respectively. Two plasmid libraries were generated by ligating the DNA to pACYC184, a low-copy-number plasmid, plated on CES200, a recombination-deficient strain of $E$. coli (Sambrook et al. 1989), and screened with the 63-bp probe. Plasmids containing the 3.7-kb BamHI-ClaI fragment and the 2.2-kb EagI$B a m H I$ fragment were named pKK9 and pKK10, respectively.

\section{Determination of mek-2 gene structure}

Table 5 shows the sequences and locations of oligonucleotide primers used. We designed primers located in exons using the mek-2 cDNA sequence (Wu et al., this issue). We designed primers located in introns using the results described below. The 5' ends of $f$ (forward) and $r$ (reverse) primers are upstream and downstream relative to the coding sequence, respectively. We used MEK- $1 \mathrm{f}$ and MEK-7r to generate an 7-kb DNA fragment using the newly developed long PCR amplification (Barnes 1994; Cheng et al. 1994). We purified this fragment using $\beta$-agarase and partially determined its sequence using an automated ABI 373A DNA sequencer (Applied Biosystems). We defined oligonucleotide primers used for sequencing without knowing the position of the introns; these primers were spaced at regular intervals in the cDNA sequence. We used MEK- $2 f,-3 f,-4 f,-5 f$, $-7 r,-8 r,-9 r$, and $-10 r$ to identify the position and exon-proximal 
Table 5. Oligonucleotide primers

\begin{tabular}{lll}
\hline Name & Sequence & Location \\
\hline MEK-1f & 5'-ATAATGTCGAGCGGAAAACGGCG & exon 1 \\
MEK-2f & 5'-GCATCAAGGAGTTGAGTGAGG & exon 2 \\
MEK-3f & 5'-CATTGTTGGATTCTACGGGGC & exon 3 \\
MEK-4f & 5'-GTTGATTGATTCGATGGC & exon 5 \\
MEK-5f & 5'-GAGCAATCCGGCGTCAATGGC & exon 6 \\
MEK-6r & 5'-CATTTCGTAGAATCACCCCC & exon 7 \\
MEK-7r & 5'-GTGTGAAGAAGACGTCTGCGG & exon 7 \\
MEK-8r & 5'-CGCCGGATTGCTCGGCGG & exon 6 \\
MEK-9r & 5'-CAACATTCCAGAGACTCC & exon 5 \\
MEK-10r & 5'-CCACAAAAGCCCCGTAGAATCC & exon 3 \\
MEK-12r & 5'-CCGAATCCGAGAATCCTGCGAG & intron 3 \\
MEK-13f & 5'-GTCTAAAAATACCAAAAAAATCCG & intron 3 \\
MEK-14r & 5'-GAAATTTCAGCTGAAATTGGTG & intron 5 \\
MEK-15f & 5'-CACAATTTCCGCTTGAAAATTC & intron 5 \\
MEK-16r & 5'-CCATTTTTTTTCTTCTTTTTTCTTCC & intron 6 \\
MEK-17f & 5'-CCAAATTGATATTCGGTATCAGG & intron 6 \\
\hline
\end{tabular}

sequence of adjacent introns. For example, we used MEK-3f, which is located in exon 3 , to identify the position of intron 3 and the sequence of intron 3 adjacent to exon 3 .

We determined the complete sequences of introns 1,2 , and 4 . Intron 3 appeared to be $\sim 3900 \mathrm{bp}$, because primers MEK-1f and MEK-8r amplified an 5700 -bp fragment from genomic DNA that included $\sim 1800 \mathrm{bp}$ of sequences from other introns and exons. Intron 5 appeared to be $\sim 840 \mathrm{bp}$, because primers MEK-4f and MEK-8r amplified an $\sim 1100$-bp fragment from genomic DNA that included $257 \mathrm{bp}$ of exon DNA. Intron 6 appeared to be $\sim 1400 \mathrm{bp}$, because primers MEK-5f and MEK-7r amplified an $\sim 1590$-bp fragment from genomic DNA that included $182 \mathrm{bp}$ of exon DNA.

\section{Determination of the sequences of mek- 2 alleles}

DNA from each of the eight mek-2 mutants was derived from homozygous mutant adult hermaphrodites (Williams et al. 1992). MEK-1f and MEK-12r were used to amplify a 685-bp fragment that included exons 1,2 , and 3 , introns 1 and 2 , and $82 \mathrm{bp}$ of intron 3. MEK-13f and MEK-14r were used to amplify a 402bp fragment that included exons 4 and 5 , intron 4, 59 bp of intron 3 and $71 \mathrm{bp}$ of intron 5. MEK-15f and MEK-16r were used to amplify a 382-bp fragment that included exon 6, 52 bp of intron 5 , and 49 bp of intron 6 . MEK-17f and MEK-6r were used to amplify a 331-bp fragment that included 69 bp of intron 6 . We determined the complete sequences of both strands of each fragment as described above. Because MEK-1f spans codons 1-7, we did not determine the sequences of the mutant alleles for these codons.

\section{Acknowledgments}

We thank Greg Beitel, Ann Rose, and Kim McKim for mek-2 alleles, Heidi Browning and John Sulston for genomic DNA libraries, and Paul Sternberg for lin-3(syIs1). We are grateful to Beth James for help sequencing DNA and Mark Metzstein for assistance with long PCR. We thank Leslie Lobel for information about the physical map, Eric Lambie for telling us that h294 is an allele of mek-2, Alan Coulson for providing sequence data, and Yan Wu and Min Han for communicating results prior to publication. Michael Koelle, Mark Metzstein, Shai Shaham, Jeff Thomas, and Sander van den Heuvel provided helpful comments about the manuscript. This research was supported by grants from the Howard Hughes Medical Institute (H.R.H.), and grants from the U.S. Public Health Service (GM51586 to K.-L.G.) and the American Cancer Society (BE-171 to K.-L.G.). K.K. was supported by a fellowship from the Leukemia Society of America. H.R.H. is an Investigator of the Howard Hughes Medical Institute.

The publication costs of this article were defrayed in part by payment of page charges. This article must therefore be hereby marked "advertisement" in accordance with 18 USC section 1734 solely to indicate this fact.

\section{References}

Ahn, N.G., R. Seger, and E.G. Krebs. 1992. The mitogen-activated protein kinase activator. Curr. Opin. Cell Biol. 4: 992-999.

Alessi, D.R., Y. Saito, D.G. Campbell, P. Cohen, G. Sithanandam, U. Rapp, A. Ashworth, C.J. Marshall, and S. Cowley. 1994. Identification of the sites in MAP kinase kinase-1 phosphorylated by p74 ${ }^{\text {raf-1 }}$. EMBO $J$. 13: 1610-1619.

Aroian, R.V., M. Koga, J.E. Mendel, Y. Ohshima, and P.W. Sternberg. 1990. The let-23 gene necessary for Caenorhabditis elegans vulval induction encodes a tyrosine kinase of the EGF receptor subfamily. Nature 348: 693-699.

Aroian, R.V. and P.W. Sternberg. 1991. Multiple functions of let-23, a Caenorhabditis elegans receptor tyrosine kinase gene required for vulval induction. Genetics 128: 251-267.

Barnes, W.M. 1994. PCR amplification of up to 35-kb DNA with high fidelity and high yield from $\lambda$ bacteriophage templates. Proc. Nat1. Acad. Sci. 91: 2216-2220.

Barton, M.K. and J. Kimble. 1990. fog-1, a regulatory gene required for specification of spermatogenesis in the germ line of Caenorhabditis elegans. Genetics 125: 29-39.

Beitel, G.J., S.G. Clark, and H.R. Horvitz. 1990. Caenorhabditis elegans ras gene let-60 acts as a switch in the pathway of vulval induction. Nature 348: 503-509.

Boguslawski, G. and J.O. Polazzi. 1987. Complete nucleotide sequence of a gene conferring polymyxin B resistance on yeast: Similarity of the predicted polypeptide to protein kinases. Proc. Natl. Acad. Sci. 84: 5848-5852.

Brenner, S. 1974. The genetics of Caenorhabditis elegans. Genetics 77: 71-94.

Brunner, D., N. Oellers, J. Szabad, W.H. Biggs III, S.L. Zipursky, and E. Hafen. 1994. A gain-of-function mutation in Drosophila MAP kinase activates multiple receptor tyrosine $\mathrm{ki}$ nase signaling pathways. Cell 76: 875-888. 
Cheng S., C. Fockler, W.M. Barnes, and R. Higuchi. 1994. Effective amplification of long targets from cloned inserts and human genomic DNA. Proc. Natl. Acad. Sci. 91: 5695-5699.

Clark, S.G., M.J. Stern, and H.R. Horvitz. 1992a. C. elegans cell-signaling gene sem-5 encodes a protein with $\mathrm{SH} 2$ and SH3 domains. Nature 356: 340-344.

- 1992b. Genes involved in two Caenorhabditis elegans cell-signaling pathways. Cold Spring Harbor Symp. Quant. Biol. 57: 363-373.

Clark, S.G., X. Lu, and H.R. Horvitz. 1994. The Caenorhabditis elegans locus lin-15, a negative regulator of a tyrosine kinase signaling pathway, encodes two different proteins. Genetics 137: 987--997.

Coulondre, C. and J.H. Miller. 1977. Genetic studies of the lac repressor. IV. Mutagenic specificity in the LacI gene of Escherichia coli. J. Mol. Biol. 117: 577-606.

Coulson, A., R. Waterston, J. Kiff, J. Sulston, and Y. Kohara. 1988. Genome linking with yeast artificial chromosomes. Nature 335: 184-186.

Cowley, S., H. Paterson, P. Kemp, and C.J. Marshall. 1994. Activation of MAP Kinase Kinase is necessary and sufficient for PC12 differentiation and for transformation of NIH 3T3 cells. Cell 77: 841-852.

Crews, C.M., A. Alessandrini, and R.L. Erikson. 1992. The primary structure of MEK, a protein kinase that phosphorylates the ERK gene product. Science 258: $478-480$.

Davis, R.J. 1993. The mitogen-activated protein kinase signal transduction pathway. J. Biol. Chem. 268: 14553-14556.

DeBondt, H.L., J. Rosenblatt, J. Jancarik, H.D. Jones, D.O. Morgan, and S.-H. Kim. 1993. Crystal structure of cyclin-dependent kinase 2. Nature 363: 595-602.

Eisenmann, D.M. and S.K. Kim. 1994. Signal transduction and cell fate specification during Caenorhabditis elegans vulval development. Curr. Opin. Genet. Dev. 4: 508-516.

Errede, B. and D.E. Levin. 1993. A conserved kinase cascade for MAP kinase activation in yeast. Curr. Opin. Cell Biol. 5: 254-260.

Ferguson, E.L. and H.R. Horvitz. 1985. Identification and characterization of 22 genes that affect the vulval cell lineages of the nematode Caenorhabditis elegans. Genetics 110: 17-72.

Ferguson, E.L., P.W. Sternberg, and H.R. Horvitz. 1987. A genetic pathway for the specification of the vulval cell lineages of Caenorhabditis elegans. Nature 326: 259-267.

Gibbs, C.S. and M.J. Zoller. 1991. Rational scanning mutagenesis of a protein kinase identified functional regions involved in catalysis and substrate interactions. I. Biol. Chem. 266: 8923-8931.

Han, M. and P.W. Sternberg. 1990. let-60, a gene that specifies cell fates during $C$. elegans vulval induction, encodes a ras protein. Cell 63: 921-931.

Han, M., R.V. Aroian, and P.W. Sternberg. 1990. The let-60 locus controls the switch between vulval and nonvulval cell fates in Caenorhabditis elegans. Genetics 126: 899-913.

Han, M., A. Golden, Y. Han, and P.W. Sternberg. 1993. C. elegans lin-45 raf gene participates in let-60 ras-stimulated vulval differentiation. Nature 363: 133-140.

Hanks, S.K., A.M. Quinn, and T. Hunter. 1988. The protein kinase family: Conserved features and deduced phylogeny of the catalytic domains. Science 241: 42-52.

Herman, R.K. and E.M. Hedgecock. 1990. Limitation of the size of the vulval primordium of Caenorhabditis elegans by lin-15 expression in surrounding hypodermis. Nature 348: 169-171.

Hill, R.J. and P.W. Sternberg. 1992. The gene lin-3 encodes an inductive signal for vulval development in $\mathrm{C}$. elegans. $\mathrm{Na}$ ture 358: 470-476.

Horvitz, H.R. and P.W. Sternberg. 1991. Multiple intercellular signalling systems control the development of the Caenorhabditis elegans vulva. Nature 351: 535-541.

Howell, A.M., S.G. Gilmour, R.A. Mancebo, and A.M. Rose. 1988. Genetic analysis of a large autosomal region in Caenorhabditis elegans by the use of a free duplication. Genet. Res. 49: 207-213.

Hsu, J.C. and N. Perrimon. 1994. A temperature sensitive MEK mutation demonstrates the conservation of the signaling pathways activated by receptor tyrosine kinases. Genes \& Dev. 8: 2176-2187.

Hu, S.-H., M.W. Parker, J.Y. Lei, M.C.J. Wilce, G.M. Benian, and B.E. Kemp. 1994. Insights into autoregulation from the crystal structure of twitchin kinase. Nature 369: 581-584.

Huang, L.S., P. Tzou, and P.W. Sternberg. 1994. The lin-15 locus encodes two negative regulators of Caenorhabditis elegans vulval development. Mol. Biol. Cell 5: 395-412.

Kimble, J. 1981. Alterations in cell lineage following laser ablation of cells in the somatic gonad of Caenorhabditis elegans. Dev. Biol. 87: 286-300.

Knighton, D.R., J. Zheng, L.F. Ten Eyck, V.A. Ashford, N-H. Xuong, S.S. Taylor, and J.M. Sowadski. 1991. Crystal structure of the catalytic subunit of cyclic adenosine monophosphate-dependent protein kinase. Science 253: 407-414.

Lackner, M.L., K. Kornfeld, L.M. Miller, H.R. Horvitz, and S.K. $\mathrm{Kim}$. 1994. A MAP kinase homolog, $m p k-1$, is involved in ras-mediated induction of vulval cell fates in Caenorhabditis elegans. Genes \& Dev. 8: 160-173.

Lange-Carter, C.A., C.M. Pleiman, A.M. Gardner, K.J. Blumer, and G.L. Johnson. 1993. A divergence in the MAP kinase regulatory network defined by MEK Kinase and Raf. Science 260: 315-319.

Mansour, S.J., W.T. Matten, A.S. Hermann, J.M. Candia, S. Rong, K. Fukasawa, G.F. Vande Woude, and N.G. Ahn. 1994. Transformation of mammalian cells by constitutively active MAP Kinase Kinase. Science 265: 966-970.

Marshall, C.J. 1994. MAP kinase kinase kinase, MAP kinase kinase and MAP kinase. Curr. Opin. Genet. Dev. 4: 82-89.

McCormick, F. 1994. Activators and effectors of ras p21 proteins. Curr. Opin. Genet. Dev. 4: 71-76.

McKim, K.S. and A.M. Rose. 1990. Chromosome I duplications in Caenorhabditis elegans. Genetics 124: 115-132.

Nadin-Davis, S.A. and A. Nasim. 1988. A gene which encodes a predicted protein kinase can restore some functions of the ras gene in fission yeast. EMBO J. 7: 985-993.

Odawara, M., T. Kadowaki, R. Yamamoto, Y. Shibasaki, K. Tobe, D. Accili, C. Bevins, Y. Mikami, N. Matsuura, Y. Akanuma, F. Takaku, S.I. Taylor, and M. Kasuga. 1989. Human diabetes associated with a mutation in the tyrosine kinase domain of the insulin receptor. Science 245: 66-68.

Posada J., N. Yew, N.G. Ahn, G.F. Vande Woude, and J.A. Cooper. 1993. Mos stimulates MAP kinase in Xenopus oocytes and activates a MAP Kinase Kinase in vitro. Mol. Cell. Biol. 13: 2546-2553.

Rodriguez-Viciana, P., P.H. Warne, R. Dhand, B. Vanhaesebroeck, I. Gout, M.J. Fry, M.D. Waterfield, and J. Downward. 1994. Phosphatidylinositol-3-OH kinase as a direct target of Ras. Nature 370: 527-532.

Ruvkun, G., V. Ambros, A. Coulson, R. Waterston, J. Sulston, and H.R. Horvitz. 1989. Molecular genetics of the Caenorhabditis elegans heterochronic gene lin-14. Genetics 121: 501-516.

Sambrook, I., E.F. Fritsch, and T. Maniatis. 1989. Molecular cloning: A laboratory manual, 2nd ed. Cold Spring Harbor Laboratory Press, Cold Spring Harbor, New York.

Satoh, T., M. Nakafuku, and Y. Kaziro. 1992. Function of Ras as a molecular switch in signal transduction. I. Biol. Chem. 
Kornfeld et al.

267: 24149-24152.

Schlessinger, J. and A. Ulrich. 1992. Growth factor signaling by receptor tyrosine kinases. Neuron 9: 383-391.

Schlessinger, J. 1994. SH2/SH3 signaling proteins. Curr. Opin. Genet. Dev. 4: 25-30.

Schnabel, H. and R. Schnabel. 1990. An organ-specific differentiation gene, pha-1, from Caenorhabditis elegans. Science 250: $686-688$.

Sternberg, P.W. and H.R. Horvitz. 1986. Pattern formation during vulval development in C. elegans. Cell 44: 761-772.

Sulston, J.E. and H.R. Horvitz. 1977. Post-embryonic cell lineages of the nematode, Caenorhabditis elegans. Dev. Biol. 56: 110-156.

Sulston, J.E. and J.G. White. 1980. Regulation and cell autonomy during postembryonic development of nongonadal structures. Dev. Biol. 78: 577-597.

Taylor, S.S., D.R. Knighton, J. Zheng, L.F. Ten Eyck, and J.M. Sowadski. 1992. Structural framework for the protein kinase family. Annu. Rev. Cell Biol. 8: 429-462.

Teague, M.A., D.T. Chaleff, and B. Errede. 1986. Nucleotide sequence of the yeast regulatory gene $S T E 7$ predicts a protein homologous to protein kinases. Proc. Natl. Acad. Sci. 83: $7371-7375$.

Tsuda, L., Y.H. Inoue, M.A. Yoo, M. Mizuno, M. Hata, Y.M. Lim, T. Adachi-Yamada, H. Ryo, Y. Masamune, and Y. Nishida. 1993. A protein kinase similar to MAP kinase activator acts downstream of the Raf kinase in Drosophila. Cell 72: 407-414.

Warbrick, E. and P.A. Fantes. 1991. The wisl protein kinase is a dosage-dependent regulator of mitosis in Schizosaccharomyces pombe. EMBO J. 10: 4291-4299.

Williams, B.D., B. Schrank, C. Huynh, R. Shownkeen, and R.H. Waterston. 1992. A genetic mapping system in Caenorhabditis elegans based on polymorphic sequence-tagged sites. Genetics 131: 609-624.

Wood, W.B. and the community of C. elegans researchers, ed. 1988. The nematode Caenorhabditis elegans. Cold Spring Harbor Laboratory, Cold Spring Harbor, New York.

Wu, Y. and M. Han. 1994. Suppression of activated Let-60 Ras protein defines a role of Caenorhabditis elegans Sur-1 MAP kinase in vulval differentiation. Genes \& Dev. 8: 147-159.

Wu, Y., M. Han, and K.-L. Guan. 1995. MEK-2, a Caenorhabditis elegans MAP kinase kinase, functions in Ras-mediated vulval induction and other developmental events. Genes \& Dev. (this issue).

Zhang, F., A. Strand, D. Robbins, M.H. Cobb, and E.J. Goldsmith. 1994. Atomic structure of the MAP kinase ERK2 at 2.3A resolution. Nature 367: 704-710.

Zheng, C.F. and K.L. Guan. 1993. Cloning and characterization of two distinct human extracellular signal-regulated kinase activator kinases, MEK1 and MEK2. I. Biol. Chem. 268: 11435-11439.

. 1994. Activation of MEK family kinases requires phosphorylation of two conserved Ser/Thr residues. EMBO I. 13: 1123-1131. 


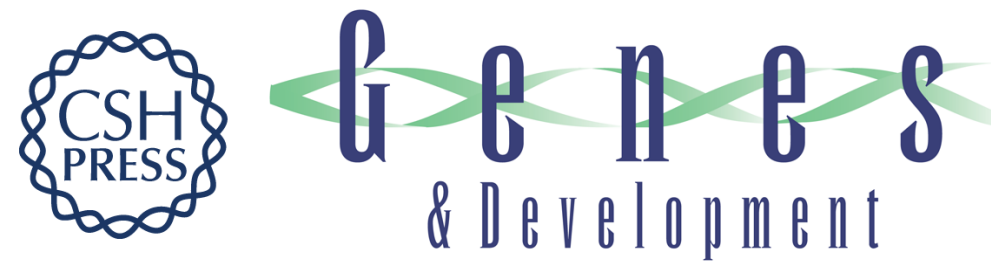

\section{The Caenorhabditis elegans gene mek-2 is required for vulval induction and encodes a protein similar to the protein kinase MEK.}

K Kornfeld, K L Guan and H R Horvitz

Genes Dev. 1995, 9:

Access the most recent version at doi:10.1101/gad.9.6.756

References This article cites 65 articles, 30 of which can be accessed free at:

http://genesdev.cshlp.org/content/9/6/756.full.html\#ref-list-1

License

Email Alerting

Service

Receive free email alerts when new articles cite this article - sign up in the box at the top right corner of the article or click here.

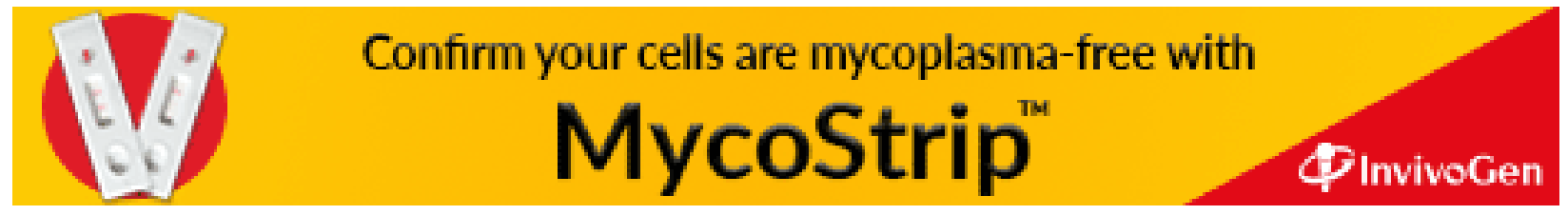

